\title{
Inbreeding depression in one of the last DFTD-free wild populations of Tasmanian devils
}

\author{
Rebecca M Gooley ${ }^{1}$, Carolyn J Hogg ${ }^{1}$, Samantha Fox ${ }^{2,3}$, David Pemberton ${ }^{2}$, Katherine Belov ${ }^{1}$, Catherine E \\ Grueber ${ }^{\text {Corresp. } 1,4}$ \\ ${ }^{1}$ School of Life and Environmental Sciences, University of Sydney, Sydney, New South Wales, Australia \\ 2 Save the Tasmanian Devil Program, Hobart, Tasmania, Australia \\ 3 Toledo Zoo, Toledo, Ohio, United States of America \\ 4 San Diego Zoo Global, San Diego, California, United States of America \\ Corresponding Author: Catherine E Grueber \\ Email address: catherine.grueber@sydney.edu.au
}

Background. Vulnerable species experiencing inbreeding depression are prone to localised extinctions because of their reduced fitness. For Tasmanian devils, the rapid spread of devil facial tumour disease (DFTD) has led to population declines and fragmentation across the species' range. Here we show that one of the few remaining DFTD-free populations of Tasmanian devils is experiencing inbreeding depression. Moreover, this population has experienced a significant reduction in reproductive success over recent years.

Methods. We used 32 microsatellite loci to examine changes in genetic diversity and inbreeding in the wild population at Woolnorth, alongside field data on breeding success from females to test for inbreeding depression.

Results. We found that maternal internal relatedness has a negative impact on litter sizes. The results of this study imply that this population may be entering an extinction vortex and that to protect the population genetic rescue should be considered. This study provides conservation managers with useful information for managing wild devils and provides support for the "Wild Devil Recovery Program" which is currently augmenting small, isolated populations. 


\section{Inbreeding depression in one of the last DFTD-free 2 wild populations of Tasmanian devils}

3 Rebecca M. Gooley ${ }^{1}$, Carolyn J. Hogg ${ }^{1}$, Samantha Fox ${ }^{2,3}$, David Pemberton², Katherine Belov ${ }^{1}$

4 \& Catherine E. Grueber ${ }^{1,4}$

1 University of Sydney, School of Life and Environmental Sciences, NSW, 2006, Australia

2 Save the Tasmanian Devil Program, Hobart, TAS, 7001, Australia

3 Toledo Zoo, 2605 Broadway, Toledo, OH43609, USA

${ }^{4}$ San Diego Zoo Global, PO Box 120551, San Diego, CA, 92112, USA

Corresponding Author: Catherine Grueber

University of Sydney, School of Life and Environmental Sciences, NSW, 2006, Australia

Email address: catherine.grueber@sydney.edu.au

\section{Abstract}

Background. Vulnerable species experiencing inbreeding depression are prone to localised extinctions because of their reduced fitness. For Tasmanian devils, the rapid spread of devil facial tumour disease (DFTD) has led to population declines and fragmentation across the species' range. Here we show that one of the few remaining DFTD-free populations of Tasmanian devils is experiencing inbreeding depression. Moreover, this population has experienced a significant reduction in reproductive success over recent years.

Methods. We used 32 microsatellite loci to examine changes in genetic diversity and inbreeding in the wild population at Woolnorth, alongside field data on breeding success from females to test for inbreeding depression.

Results. We found that maternal internal relatedness has a negative impact on litter sizes. The results of this study imply that this population may be entering an extinction vortex and that to protect the population genetic rescue should be considered. This study provides conservation managers with useful information for managing wild devils and provides support for the "Wild Devil Recovery Program" which is currently augmenting small, isolated populations.

\section{Introduction}

For threatened species, a reduction in reproductive success can severely impact population persistence. The Tasmanian devil, Sarcophilus harrisii, is one such species that has a decline of up to $80 \%$ in areas affected by an infectious clonal cancer, devil facial tumour disease (DFTD) (Loh et al. 2006; Pye et al. 2016; Lazenby et al. 2018). As the apex carnivore in Tasmania, devil population declines are causing trophic cascades in the Tasmanian ecosystem (Hollings et al. 2014) and recent modelling has indicated that these populations will begin to succumb to small population genetic pressures (Grueber et al. 2019). Declining populations are at risk of reduced 
37

gene flow and loss of genetic diversity (relative to larger, more connected populations) as an outcome of genetic drift and inbreeding (Charlesworth \& Willis 2009).

Since the discovery of DFTD in the mid-1990s in the north-east of Tasmania, the national and international conservation community has come together and research into Tasmanian devil biology has grown rapidly, including studies of DFTD epidemiology (e.g. Hamede et al. 2008; McCallum et al. 2009; Hamede et al. 2012), devil behaviour (e.g. Sinn et al. 2014), ecological impacts (e.g. Hollings et al. 2014), population genetics (e.g. Lachish et al. 2011; Grueber et al. 2015; Epstein et al. 2016; Hendricks et al. 2017), ex situ conservation (e.g. Hogg et al. 2016) and translocations (e.g. Rogers et al. 2016; Thalmann et al. 2016; Wise et al. 2016; Grueber et al. 2017). As DFTD spread from the north-east across Tasmania, devil populations have been monitored by the Save the Tasmanian Devil Program (STDP) since 2004 (Lazenby et al. 2018). The disease has spread in a generally south-westward direction, and is now known to exist across most of the state of Tasmania, with disease-free areas limited to the north-west and south-west of the state (Pemberton 2019). One of these last-known DFTD-free populations is located at Woolnorth $\left(40.77^{\circ} \mathrm{S}, 144.77^{\circ} \mathrm{E}\right)$, north-west Tasmania (Farquharson et al. 2018; Lazenby et al. 2018). Since 2014, this population has suffered an extreme decline in reproductive output, the cause of which remains unclear (Farquharson et al. 2018). That is, between 2004 and 2009, the proportion of females breeding at Woolnorth was between 60 and $80 \%$, however between 2014 and 2016 the proportion of females breeding was approximately $20 \%$, a $40-60 \%$ reduction in a five-year period (Farquharson et al. 2018). Although for a number of carnivorous marsupials a correlation between climate and litter sizes has been shown (Fisher et al. 2001; Collett et al. 2018), this does not appear to be the sole driver of the reduction of female reproductive output in Tasmanian devils at Woolnorth (Farquharson et al 2018).

Here we aimed to test whether the observed decline in wild devil reproductive fitness (specifically litter size; devils have a maximum litter size of four pouch young; Guiler 1970) is a result of accumulating inbreeding. Inbreeding depression occurs when an accumulation of deleterious recessive alleles lowers individual heterozygosity, negatively impacting individual fitness relative to less-inbred individuals or populations (Keller \& Waller 2002; Frankham et al. 2017). Previous genetic research on a captive Tasmanian devil population revealed interindividual variation in inbreeding, but no signs of inbreeding depression (Gooley et al. 2017). Although inbreeding depression is easier to study in controlled environments (such as captivity), it may be more consequential in the wild, as environmental conditions are more severe (Joron \& Brakefield 2003; Armbruster \& Reed 2005; de Boer et al. 2015). Thus, studies of inbreeding depression in captive environments may underestimate the impact of inbreeding on fitness in the wild (Kristensen et al. 2008; Gooley et al. 2017). In addition, wild populations that experience inbreeding depression are more vulnerable to extinction (Keller \& Waller 2002), and so isolated populations may need genetic rescue to combat the effects of inbreeding (Frankham 2015; Frankham et al. 2017).

Here we use multilocus heterozygosity to investigate inbreeding and inbreeding depression in the DFTD-free population of devils at Woolnorth. We aimed to test: 1) whether inbreeding is occurring in the devil population at Woolnorth, and 2) whether inbreeding is associated with the observed reduction in reproduction (specifically litter sizes). The results of 
80 this study will inform the ongoing management of fragmented devil populations in the face of

81 DFTD.

\section{Materials \& Methods}

\section{Sample collection and genotyping}

Samples were collected by the STDP following their Standard Operating Procedure (see Appendix 5 in Hogg et al. 2019) and shared with the University of Sydney for genetic analysis. DNA samples and corresponding reproductive and demographic data were available for years 2006, 2007, 2009, 2014, 2015 and 2016. Reproductive output for females was taken as the estimated count of offspring produced (i.e. "litter size"), following Farquharson et al. (2018). Female devils are limited to a maximum of 4 offspring per breeding event (Guiler 1970). As is standard practice for documenting reproductive output in Tasmanian devils (following Keeley et al. 2012; Farquharson et al. 2018), litter size was estimated by the presence and count of pouch young for all years except 2009. The 2009 monitoring trip occurred later in the year, so litter size was estimated by the presence and count of active teats (indicating pouch young had been denned). As devils are marsupials, pouch young attach to the teat shortly after birth, and remain attached for approximately 4 months. Unoccupied teats where no pouch young attach after birth will noticeably regress (Hesterman et al. 2008). Denned devils ( 5-10 months post birth) will continue to suckle keeping the teat active providing an indication of the number of offspring that had birthed and attached to a teat. In total, 168 wild Tasmanian devils (90 females and 78 males) were included in this study; none provided replicate measurements. Male reproductive output could not be examined in this study due to the open nature of the population, making pedigree reconstruction from genetic data difficult.

DNA from ear biopsy samples from the 2006, 2007 and 2009 monitoring trips had been previously extracted (Hendricks et al. 2017), whilst samples from 2014, 2015 and 2016 were extracted using a phenol-chloroform technique (Sambrook et al. 1989) and stored at $-20^{\circ} \mathrm{C}$. Samples were genotyped with 32 putatively neutral microsatellite markers following Gooley et al. (2017) and Jones et al. (2003). A randomly chosen set of $7 \%$ were re-genotyped to estimate genotyping error. We tested for null alleles at each locus using Micro-Checker (van Oosterhout et al. 2004), null allele frequencies per year and per locus were calculated using the method of Brookfield (1996) and tabulated via Genepop (Raymond \& Rousset 1995; Rousset 2008). GenAIEx (Peakall \& Smouse 2006, 2012) was used to calculate observed $\left(\mathrm{H}_{\mathrm{O}}\right)$ and expected heterozygosity $\left(\mathrm{H}_{E}\right)$ for each locus, each year, and conduct Hardy-Weinberg exact tests.

\section{Inbreeding and inbreeding depression}

Internal relatedness (IR), a multilocus heterozygosity statistic that is expected to be positively correlated with individual inbreeding coefficient (Amos et al. 2001), was calculated using the function GENHET (Coulon 2010) for R (R Core Team 2019). IR incorporates allele frequencies, because there is a higher chance that rare-allele homozygosity is the result of inbred mating, relative to common-allele homozygosity (Amos et al. 2001). All available samples, male and female, were used to estimate allele frequencies and calculate IR, so to minimise impact of yearly allele frequency chances of calculated IR values. Across our dataset, IR was very highly correlated with other common measures of multilocus heterozygosity (such as standardised 
121

122

123

124

125

126

127

128

129

130

131

132

133

134

135

136

137

138

139

140

141

142

143

144

145

146

147

148

149

150

151

152

153

154

155

156

157

158

159

160

161

162

163

observed heterozygosity, and heterozygosity-by-loci; all absolute correlation coefficients were $\geq 0.94$ ), so we focussed our main statistical analyses on IR.

We examined whether inbreeding was accumulating among individuals in the population by testing for a change in IR over time using a linear model fitted in $\mathrm{R}$ with year as the fixed predictor and IR as the response $(\mathrm{N}=168)$. We evaluated change in the population-level of inbreeding $\left(F_{I S}\right)$, calculated using the package hierfstat (Goudet 2005) for $R$.

To interpret associations between heterozygosity and litter sizes as inbreeding depression, molecular data must reflect variation in inbreeding levels among individuals, i.e. identity disequilibrium (Szulkin et al. 2010). This variation was quantified with the $g_{2}$ statistic (David et al. 2007; Szulkin et al. 2010), using the package inbreedR (Stoffel et al. 2016) for R, with its precision evaluated using 1,000 Monte Carlo iterations.

We tested for inbreeding depression by determining whether IR was a predictor of female litter size using linear regression. The equations used for the regression were:

- Litter size: $\quad \operatorname{logit}\left(\frac{\text { litter size }}{4}\right)=\beta_{0}+\beta_{1} I R_{i}+\beta_{2}$ age $_{i}+\beta_{3}$ year $_{i}+\varepsilon_{i}$

- Probability of breeding: $\quad \operatorname{logit}\left(P_{\text {breed }}\right)=\beta_{0}+\beta_{1} I R_{i}+\beta_{2}$ age $_{i}+\beta_{3}$ year $_{i}+\varepsilon_{i}$ Where $\beta_{0}$ is the intercept, $\beta_{1-3}$ are regression coefficients associated with the specified predictor variables, and $\varepsilon_{i}$ is the error term. We also attempted to add year as a random fixed factor (e.g. following Barr et al. 2013), but only our litter size model converged. Those results were qualitatively similar to our main findings, and so are presented in Supplementary Results for comparison. Litter size was modelled as a binomial response using the cbind function in the $\mathrm{R}$ base package, where the number of offspring was the number of binomial "events" and the number of trials was 4 (maximum possible litter size). The litter size model was fitted twice: once with the litter sizes of all females $(\mathrm{N}=90)$ and with only those females that showed evidence of breeding (i.e. producing 1 or more offspring, $\mathrm{N}=36$ ). Inbreeding depression is expected to produce a negative slope for IR (our predictor of interest), i.e. increased IR is associated with decreased litter sizes. Age (based on tooth wear observations, Pemberton 1990) and year were also included as continuous fixed predictors (with year $=0$ for 2006). Model selection was conducted using an information theoretic approach following Grueber et al (2011), with standardisation following Gelman (Gelman 2008) using the package arm (Gelman \& Su 2015), and multimodel inference performed using the package MuMIn (Barton 2009). We report the final model effect sizes and their $95 \%$ confidence intervals (based on $1.96 \times$ adjusted SE), in addition to their relative importance ( $\mathrm{RI}$, sum of Akaike weights), and the $R^{2}$ of the global model calculated using the package rsq (Zhang 2018).

To consider the effects of individual loci in generating HFCs (i.e. "local effects"; see Szulkin et al. 2010), we tested the hypothesis that heterozygosity of some loci may be individually more informative of variation in fitness than a statistic that measures the combined effect of all loci. This prediction would be upheld if an overall effect of multilocus heterozygosity is driven by only one or a few loci. It is important to note that, under inbreeding, heterozygosity values of individual loci are not independent, and so it is the magnitudes of relative effect sizes that are important (Szulkin et al. 2010). The most widely-cited method for testing the local effects hypothesis uses multiple regression, whereby each locus is fitted simultaneously, and the slopes compared (Szulkin et al. 2010). This method requires a complete dataset (no missing genotype data, as incomplete cases are excluded from standard multiple regressions; 
164 Nakagawa \& Freckleton 2008) and, to avoid overfitting, a large sample size relative to the 165 number of loci. In linear regression, a ratio of cases:predictors of approximately $10-20$ is

166

167

168

169

170

171

172

173

174

175

176

177

178

179

180

181

182

183

184

185

186

187

188

189

190

191

192

193

194

195

196

197

198

199

200

201

202

203

204

205

recommended for fitting a statistically robust regression (Harrell 2015). For our dataset, we had 32 loci and 69 complete cases (females with no missing genotype data), falling far short of the recommended data required for this method. We therefore approached the need to model our loci separately but simultaneously, and alongside multilocus heterozygosity, by using an information theoretic approach. We considered the effect of a locus' heterozygosity on fitness as an independent local-effect hypothesis by fitting separate models for each locus, and considered all loci collectively by ranking and comparing their AIC values to draw inference based on both the degree of support for each of model, and the effect sizes (slopes) of heterozygosity. Our model set included:

- Single-locus models, which include observed heterozygosity of each locus fitted separately (coded as a 0/1 for homozygote/heterozygote; following Grueber et al. [2013]); 32 models in total. These models all also include informative non-genetic parameters (as in the "base" model, see below).

- A "base" model, which excluded heterozygosity data altogether. This model can be considered as our null hypothesis for the purposes of examining local effects, including any non-genetic parameters that were found to influence fitness in our main analysis (namely Year, see Results).

- An " $\mathrm{H}_{\mathrm{O}}$ " multilocus heterozygosity model, which fits observed $\mathrm{H}_{\mathrm{O}}$ averaged across all loci. The $\mathrm{H}_{\mathrm{O}}$ statistic was used as our multilocus measure (as opposed to IR) to facilitate direct comparison with the single-locus models. The $\mathrm{H}_{\mathrm{O}}$ model also includes informative non-genetic parameters (as in the "base" model).

All 34 models were quantitatively ranked and compared using AIC; our "base" and " $\mathrm{H}_{\mathrm{O}}$ " models served as reference points for calculating $\triangle \mathrm{AIC}$. Models with lower AIC are interpreted as having stronger support, and $|\triangle A I C|<2$ as models with similar levels of support (Burnham \& Anderson 1998). We note that the reduced dataset of $N=69$ females produced qualitatively the same results as in our main analysis.

\section{Results}

Inferred null allele frequencies were very low for most loci/years (Table 1), and we had little missing data: $>90 \%$ of individuals were successfully genotyped for $>90 \%$ of loci. Genotyping error rate was $0.6 \%$. Microsatellite diversity of Woolnorth devils was low (Table 1), and similar to observations of other wild sites and captive populations (e.g. Gooley et al. 2017; Storfer et al. 2017; Grueber et al. 2019). Levels of IR remained constant across the study period (linear regression: $\beta_{\text {year }}=0.003 \pm 0.005 \mathrm{SE}, p=0.546 ; \beta_{0}=-5.621 \pm 9.295 \mathrm{SE}, \mathrm{p}=$ $0.546, N=168$ devils, Figure 1a). The same result was obtained when using observed heterozygosity, which does not take allele frequencies into account (linear regression: $\beta_{\text {year }}=$ $-0.002 \pm 0.002$ SE, $p=0.303 ; \beta_{0}=4.400 \pm 3.896$ SE, $p=0.260, N=168$ devils). Similarly, considering inbreeding at the population level in respect of Hardy-Weinberg equilibrium ( $\left.F_{I S}\right)$, we also found no trend over time (Figure 1b).

We were able to assess inbreeding using our dataset as we detected statistically significant identity disequilibrium $\left(g_{2}=0.017\right.$, SE $=0.007, p$-value $\left.=0.003\right)$, indicating that

Peer) reviewing PDF | (2019:09:40836:3:0:CHECK 22 Apr 2020) 
variation at our molecular markers reflects variation in the level of inbreeding among individuals.

We found evidence that inbreeding depression is occurring in the female devil population at Woolnorth as IR had a strong negative effect on overall female litter sizes (increased homozygosity [IR] was associated with decreased fitness) (Table 2). We found little evidence of an effect of IR on propensity to breed at all (weak effect size, wide error, poor relative importance; Table 2), but when examining only those females that had at least one offspring, the effect of IR that was seen for overall litter size was confirmed (Table 2). We therefore infer our overall results are not driven by effects of IR on breeding per se, but that the inbreeding depression applies primarily to litter size specifically.

Considering locus-by-locus effects of heterozygosity on litter size, we found compelling evidence that three loci (Sha3o, Sha32 and Sha013) are stronger determinants of litter size than multilocus heterozygosity. This result is inferred based on those single-locus models having substantially greater support than that of the multilocus estimator $(\triangle A I C>4$; Table 3$)$. The relative effect sizes of these loci (slope of heterozygosity) are all weaker than the multilocus model (Table 3) suggesting that these findings are not consistent with strong local effects. For example, two of the strongest-effect loci (Sh3o and Sha32) showed reduced fitness in heterozygotes relative to homozygotes; i.e. a negative effect of heterozygosity, which is opposite to predictions under inbreeding depression and opposite to the main effect of $\mathrm{H}_{\mathrm{O}}$. (Table 3). Although Sha013 showed improved fitness in heterozygotes (consistent with predictions), its effect was much weaker than seen in the multilocus model $\left(\beta_{H_{O}}(\right.$ Sha013) $=$ $1.196 \pm 0.399 \mathrm{SE}$, while $\beta_{H_{O}}$ (multilocus) $=4.260 \pm 1.847 \mathrm{SE}$; Table 3). For the three loci with greatest evidence of an effect of an HFC, Sh3o and Sha013 had moderate rates of heterozygosity, while for Sha32 only five heterozygotes were observed in the reduced sample (frequency 0.072, $N=69$; Table 3). Of these five Sha32 heterozygotes, four were observed in the "early" part of the study, when reproductive rates were generally high (negative effect of Year in our modelling, Table 2, Table 3), but only two produced litters, which were small (two joeys each). The observed Sha32 data for this small sample set is therefore consistent with the negative trend seen in the modelling results (heterozygotes produced fewer offspring than expected); more data would be required to confirm this pattern.

Five further loci (Sha040, Sha039, Sh2g, Sh2p and Sh6e) have similar levels of singlelocus model support as the multilocus estimator $(|\triangle \mathrm{AIC}|<2)$; their effects on fitness were all positive (in line with predictions and consistent with the multilocus predictor), and all were weaker than the multilocus predictor (compare the $\beta_{H_{O}}$ values in Table 3 ). No other single-locus models were superior to the multilocus model for explaining litter size (Table 3 ). As none of the slopes of our strongest single-locus effects are of greater magnitude than the main effect of multilocus heterozygosity, we interpret our results as consistent with general (genome-wide) effects, i.e. inbreeding depression.

\section{Discussion}

Here, we show that one of the last-known DFTD-free wild populations of Tasmanian devils is experiencing inbreeding depression. Although our data did not detect an increase in inbreeding 
247 over the timescale of our study, we did show that maternal IR has a negative impact on

248 reproductive output (litter size) in wild devils. A previous study observed a significant decline in

249 reproduction over time at Woolnorth (Farquharson et al. 2018). It is unclear whether inbreeding

250 depression may be either partially responsible for this trend, or a worrying consequence of it.

251 However when these past observations are considered alongside the findings of the current

252 study, we suggest that the Woolnorth population may be close to a tipping point, whereby

253 inbreeding reduces reproductive rates (perhaps in concert with other factors), which in turn

254 further reduces population size and exacerbates the occurrence of inbreeding and inbreeding

255 depression. This raises the management option of genetic rescue for Woolnorth, whereby

256 supplementation could increase the reproductive fitness of this population, which is now

257 effectively isolated due to devil facial tumour disease causing $80 \%$ declines in adjacent devil

258 populations (Whiteley et al. 2015; Lazenby et al. 2018).

259

260

Small populations that exist in fragmented landscapes are expected to increase in mean inbreeding levels over time (Wright et al. 2007; Frankham et al. 2017) and monitoring this

261

262

263 process is an important element of genetic management in conservation (Fredrickson et al. 2007; La Haye et al. 2012). Interestingly, for our study, the effects of inbreeding were most influential on litter size and not on a female's propensity to breed. This result suggests

264

265 inbreeding as a likely causative agent in the decline in litter size previously reported

266

267 (Farquharson et al. 2018). Given the short time-frame of the study (2006 - 2016), our failure to detect a corresponding change in IR over time may indicate that a substantive increase in population mean inbreeding levels is yet to occur. This interpretation is not unprecedented: for example, the southernmost Swedish population of arctic fox did not show an increase in inbreeding coefficients until four years after population fragmentation that occurred in the late

270

271 1990s (Noren et al. 2016). In any case, the declining reproductive output seen here, and previously (Farquharson et al. 2018), could lead to a decrease in effective population size. As of 2018, the low reproductive output of the Woolnorth population continues (STDP, unpublished data). As a short-lived carnivorous marsupial species, ongoing reductions in litter sizes will more than likely impact long-term population dynamics (Fisher et al. 2001). If this is an accurate interpretation, the likely consequence of these processes will be an eventual increase in inbreeding, and a strengthening of its negative effects. To test this hypothesis, it will be important to continue monitoring the trajectory of demographic and genetic processes in this

278

279

280

281

282

283

284 population, given its importance as the last DFTD-free wild population of Tasmanian devils.

Devil populations, with and without DFTD, are fragmented across the landscape, so inbreeding depression may be occurring at other sites, particularly those affected by DFTD. It would be informative to continue to quantify inbreeding depression into the future to facilitate effective management of wild populations. Evidence of inter-individual variation in inbreeding at Woolnorth ( $g_{2}$ analysis) indicates that we have the molecular tools available to test for inbreeding depression; the next step is to determine whether this is also true for other sites. Our

285

286

287

288

289 results presented here contribute to the growing body of literature that is assisting the STDP to predict the outcomes of their management strategy of augmenting small wild populations to promote gene flow (Fox \& Seddon 2019; Grueber et al. 2019).

Extensive modelling will be informative for predicting the long-term consequences of reduced reproductive output on devil population dynamics and growth. At sites where DFTD is

290 present, there have been observed increases in precocial breeding ( 1 year olds breeding) and 
291

292

293

294

295

296

297

298

299

300

301

302

303

304

305

306

307

308

309

310

311

312

313

314

\section{Conclusions}

316

317

318

319

320

321

322

323

324

325

\section{6}

327

328

329

330 DNA extractions.

increased litter sizes, highlighting the complex interplay between reproductive parameters and population sustainability in the presence of DFTD (Jones et al. 2008; Grueber et al. 2018; Lazenby et al. 2018). However, the degree to which this population compensation permits longterm population growth is still unclear (Lazenby et al 2018), and it is similarly unclear whether similar processes will occur in the face of inbreeding depression. Previous modelling to assess the retention of rare alleles at DFTD-present sites when population sizes are small showed that population supplementation would be required to ensure long-term genetic viability (Grueber et al 2019). To predict the long-term consequences of the inbreeding depression observed here, a more comprehensive modelling exercise is required. These models need to account for possible trade-offs and interactions among inbreeding, reproductive dynamics, changes in survivorship in the presence of DFTD, and other ecological parameters such as the impact of drought/changing climate, roadkill, habitat fragmentation etc. We also acknowledge that translocations carry risks, which are incorporated into management planning when determining the cost/benefit trade-off of supplementing wild populations (Ewen et al. 2012). For example, in addition to common concerns such as survival rates (e.g. Thalmann et al. 2016), the Save the Tasmanian Devil Program also considers the potential for vehicle strike (e.g. Grueber et al. 2017) and other behavioural factors (e.g. Sinn et al. 2014), microbiome changes (e.g. Chong et al. 2019) and variation in the genetic contributions of translocated individuals (e.g. McLennan et al. 2018). Consideration of the genetic impacts of translocation is critical for ensuring the long-term persistence of managed populations (Weeks et al. 2011). For wild devils, it would be valuable to consider the interplay between the apparent costs of inbreeding depression (this study) and genetic diversity loss (e.g. Grueber et al. 2019) in an analysis that also incorporates the effects of DFTD on demography (e.g. Jones et al. 2008; Grueber et al. 2018; Lazenby et al. 2018) and genetic structure (e.g. Lachish et al. 2011; Epstein et al. 2016).

We have documented the first evidence of inbreeding depression in a wild population of Tasmanian devils. Whether inbreeding is the driver of the observed reproductive decline at Woolnorth, and/or whether the reproductive decline is driving an increase in inbreeding cannot be specifically determined. Although the long-term impact of this reduced productivity on population growth is unknown at this time, our data do show that inbreeding is detrimental to reproductive output in this population, and has the potential to become more prevalent. Augmenting this population with genetic material from other locations across Tasmania may alleviate the effects of future inbreeding and minimise the occurrence of inbreeding depression. Ongoing monitoring after augmentation will provide valuable insights to the impacts of supplementation on population growth and inbreeding.

\section{Acknowledgements}

We thank the Save the Tasmanian Devil Program for the collection of samples over the years of this study; this research could not be conducted without their hard work. Thanks also to B.

Lazenby for valuable comments on the draft manuscript and E. Johnson for assistance with

Peer] reviewing PDF | (2019:09:40836:3:0:CHECK 22 Apr 2020) 


\section{References}

332

333

334

335

336

337

338

339

340

341

342

343

344

345

346

347

348

349

350

351

352

353

354

355

356

357

358

359

360

361

362

363

364

365

366

367

368

369

370

371

372

373

374

375

376

377

378

379

380

381

382

383
Amos W, Worthington Wilmer J, Fullard K, Burg TM, Croxall JP, Bloch D, Coulson T (2001) The influence of parental relatedness on reproductive success. Proceedings of the Royal Society of London Series B: Biological Sciences, 268, 2021-2027.

Armbruster P, Reed DH (2005) Inbreeding depression in benign and stressful environments. Heredity, 95, 235-242.

Barr DJ, Levy R, Scheepers C, Tily HJ (2013) Random effects structure for confirmatory hypothesis testing: Keep it maximal. Journal of Memory and Language, 68, 255-278.

Bartoń K (2009) MuMIn: multi-model inference. Available at http://r-forge.r-project.org/projects/mumin/.

Brookfield JFY (1996) A simple new method for estimating null allele frequency from heterozygote deficiency. Molecular Ecology, 5, 453-455.

Burnham KP, Anderson DR (1998) Model selection and multimodel inference. Springer, Berlin.

Charlesworth D, Willis JH (2009) The genetics of inbreeding depression. Nature Review Genetics, 10, 783-796.

Chong R, Grueber CE, Fox S, Wise P, Barrs VR, Hogg CJ, Belov K (2019) Looking like the locals - gut microbiome changes post-release in an endangered species. Animal Microbiome, 1, 8.

Collett RA, Baker AM, Fisher DO (2018) Prey productivity and predictability drive different axes of lifehistory variation in carnivorous marsupials. Proceedings of the Royal Society B: Biological Sciences, 285, 20181291.

Coulon A (2010) GENHET: an easy-to-use R function to estimate individual heterozygosity. Molecular Ecology Resources, 10, 167-169.

David P, Pujol B, Viard F, Castella V, Goudet J (2007) Reliable selfing rate estimates from imperfect population genetic data. Molecular Ecology, 16, 2474-2487.

de Boer RA, Eens M, Fransen E, Muller W (2015) Hatching asynchrony aggravates inbreeding depression in a songbird (Serinus canaria): an inbreeding-environment interaction. Evolution, 69, 1063-1068.

Epstein B, Jones M, Hamede R, Hendricks S, McCallum H, Murchison EP, Schonfeld B, Wiench C, Hohenlohe P, Storfer A (2016) Rapid evolutionary response to a transmissible cancer in Tasmanian devils. Nature Communications, 7, 12684.

Ewen JG, Armstrong DP, Parker KA, Seddon PJ (2012) Reintroduction Biology: Integrating Science and Management. Blackwell Publishing.

Farquharson KA, Gooley RM, Fox S, Huxtable S, Belov K, Pemberton D, Hogg CJ, Grueber CE (2018) Are any populations 'safe'? Unexpected reproductive decline in a population of Tasmanian devils free of devil facial tumour disease. Wildlife Research, 45, 31-37.

Fisher DO, Owens IPF, Johnson CN (2001) The ecological basis of life history variation in marsupials. Ecology, 82, 3531-3540.

Fox S, Seddon PJ (2019) Wild devil recovery: managing devils in the presence of disease. Pages 141148 in C. J. Hogg, S. Fox, D. Pemberton, and K. Belov, editors. Saving the Tasmanian Devil: recovery through science based management. CSIRO Publishing, Melbourne, Australia.

Frankham R (2015) Genetic rescue of small inbred populations: meta-analysis reveals large and consistent benefits of gene flow. Molecular Ecology, 24, 2610-2618.

Frankham R, Ballou JD, Ralls K, Eldridge M, Dudash MR, Fenster CB, Lacy RC, Sunnucks P (2017) Genetic management of fragmented animal and plant populations. Oxford University Press.

Fredrickson RJ, Siminski P, Woolf M, Hedrick PW (2007) Genetic rescue and inbreeding depression in Mexican wolves. Proceedings of the Royal Society B, 274, 2365-2371.

Gelman A (2008) Scaling regression inputs by dividing by two standard deviations. Statistics in Medicine, 27, 2865-2873.

Gelman A, Su YS (2015) arm: Data analysis using regression and multilevel/hierarchical models. Available at http://CRAN.R-project.org/package=arm.

Gooley R, Hogg CJ, Belov K, Grueber CE (2017) No evidence of inbreeding depression in a Tasmanian devil insurance population despite significant variation in inbreeding. Scientific Reports, 7, 1830.

Goudet J (2005) hierfstat, a package for $r$ to compute and test hierarchical F-statistics. Molecular Ecology Notes, 5, 184-186.

PeerJ reviewing PDF | (2019:09:40836:3:0:CHECK 22 Apr 2020) 
384

385

386

387

388

389

390

391

392

393

394

395

396

397

398

399

400

401

402

403

404

405

406

407

408

409

410

411

412

413

414

415

416

417

418

419

420

421

422

423

424

425

426

427

428

429

430

431

432

433

434

435

436

437

438

439

Grueber CE, Fox S, Belov K, Pemberton D, Hogg CJ (2018) Landscape-level field data reveal broadscale effects of a fatal, transmissible cancer on population ecology of Tasmanian devil. Mammalian Biology - Zeitschrift für Säugetierkunde, 91, 41-45.

Grueber CE, Fox S, McLennan EA, Gooley RM, Pemberton D, Hogg CJ, Belov K (2019) Complex problems need detailed solutions: Harnessing multiple data types to inform genetic management in the wild. Evolutionary Applications, 12, 280-291.

Grueber CE, Nakagawa S, Laws RJ, Jamieson IG (2011) Multimodel inference in ecology and evolution: challenges and solutions. Journal of Evolutionary Biology, 24, 699-711.

Grueber CE, Peel E, Gooley RM, Belov K (2015) Genomic insights into a contagious cancer in Tasmanian devils. Trends in Genetics, 31, 528-535.

Grueber CE, Reid-Wainscoat EE, Fox S, Belov K, Shier DM, Hogg CJ, Pemberton D (2017) Increasing generations in captivity is associated with increased vulnerability of Tasmanian devils to vehicle strike following release to the wild. Scientific Reports, 7, 2161.

Grueber CE, Wallis GP, Jamieson IG (2013) Genetic drift outweighs natural selection at toll-like receptor (TLR) immunity loci in a re-introduced population of a threatened species. Molecular Ecology, 22, 4470-4482.

Guiler E (1970) Observations on the Tasmanian Devil, Sarcophilus harrisii (Marsupialia : Dasyuridae) II. Reproduction, breeding and growth of pouch young. Australian Journal of Zoology, 18, 63-70.

Hamede R, Bashford J, Jones M, McCallum H (2012) Simulating devil facial tumour disease outbreaks across empirically derived contact networks. Journal of Applied Ecology, 49, 447-456.

Hamede RK, McCallum H, Jones M (2008) Seasonal, demographic and density-related patterns of contact between Tasmanian devils (Sarcophilus harrisii): Implications for transmission of devil facial tumour disease. Austral Ecology, 33, 614-622.

Harrell FE (2015) Regression Modeling Strategies. Springer, Cham.

Hendricks S, Epstein B, Schönfeld B, Wiench C, Hamede R, Jones M, Storfer A, Hohenlohe P (2017) Conservation implications of limited genetic diversity and population structure in Tasmanian devils (Sarcophilus harrisii). Conservation Genetics, 18, 977-982.

Hesterman H, Jones SM, Schwarzenberger F (2008) Pouch appearance is a reliable indicator of the reproductive status in the Tasmanian devil and the spotted-tailed quoll. Journal of Zoology, 275, 130138.

Hogg CJ, Fox S, Pemberton D, Belov K, editors (2019) Saving the Tasmanian devil: recovery through science-based management. CSIRO Publishing, Clayton South.

Hogg CJ, Lee AV, Srb C, Hibbard C (2016) Metapopulation management of an endangered species with limited genetic diversity in the presence of disease: the Tasmanian devil Sarcophilus harrisii. International Zoo Yearbook, 51, 1-17.

Hollings T, Jones M, Mooney N, Mccallum H (2014) Trophic cascades following the disease-induced decline of an apex predator, the Tasmanian devil. Conservation Biology, 28, 63-75.

Jones M, Paetkau D, Geffen E, Moritz C (2003) Microsatellites for the Tasmanian devil (Sarcophilus laniarius). Molecular Ecology Notes, 3, 277-279.

Jones ME, Cockburn A, Hamede R, Hawkins C, Hesterman H, Lachish S, Mann D, McCallum H, Pemberton D (2008) Life-history change in disease-ravaged Tasmanian devil populations.

Proceedings of the National Academy of Sciences of the United States of America, 105, 10023-10027.

Joron M, Brakefield PM (2003) Captivity masks inbreeding effects on male mating success in butterflies. Nature, 424, 191-194.

Keeley T, O'Brien JK, Fanson BG, Masters K, McGreevy PD (2012) The reproductive cycle of the Tasmanian devil (Sarcophilus harrisii) and factors associated with reproductive success in captivity. General and Comparative Endocrinology, 176, 182-191.

Keller LF, Waller DM (2002) Inbreeding effects in wild populations. Trends in Ecology and Evolution, 17, 230-241.

Kristensen T, Loeschcke V, Hoffmann A (2008) Linking inbreeding effects in captive populations with fitness in the wild: release of replicated Drosophila melanogaster lines under different temperatures. Conservation Biology, 22, 189-199.

La Haye MJJ, Koelewijn HP, Siepel H, Verwimp N, Windig JJ (2012) Genetic rescue and the increase of litter size in the recovery breeding program of the common hamster (Cricetus cricetus) in the Netherlands. Relatedness, inbreeding and heritability of litter size in a breeding program of an endangered rodent. Hereditas, 149, 207-216.

Peer) reviewing PDF | (2019:09:40836:3:0:CHECK 22 Apr 2020) 
440

441

442

443

444

445

446

447

448

449

450

451

452

453

454

455

456

457

458

459

460

461

462

463

464

465

466

467

468

469

470

471

472

473

474

475

476

477

478

479

480

481

482

483

484

485

486

487

488

489

490

491

492

493

494

495

Lachish S, Miller KJ, Storfer A, Goldizen AW, Jones ME (2011) Evidence that disease-induced population decline changes genetic structure and alters dispersal patterns in the Tasmanian devil. Heredity, 106, 172-182.

Lazenby BT, Tobler MW, Brown WE, Hawkins CE, Hocking GJ, Hume F, Huxtable S, lles P, Jones ME, Lawrence C, Thalmann S, Wise P, Williams H, Fox S, Pemberton D (2018) Density trends and demographic signals uncover the long-term impact of transmissible cancer in Tasmanian devils. Journal of Applied Ecology, 1365-2664.

Loh R, Bergfeld J, Hayes D, O'Hara A, Pyecroft S, Raidal S (2006) The pathology of devil facial tumor disease (DFTD) in Tasmanian devils (Sarcophilus harrisii). Veterinary Pathology, 43, 890-895.

McCallum H, Jones M, Hawkins C, Hamede R, Lachish S, Sinn DL, Beeton N, Lazenby B (2009) Transmission dynamics of Tasmanian devil facial tumor disease may lead to disease-induced extinction. Ecology, 90, 3379-3392.

McLennan EA, Gooley RM, Wise P, Belov K, Hogg CJ, Grueber CE (2018) Pedigree reconstruction using molecular data reveals an early warning sign of gene diversity loss in an island population of Tasmanian devils (Sarcophilus harrisii). Conservation Genetics, 19, 439-450.

Nakagawa S, Freckleton RP (2008) Missing inaction: the dangers of ignoring missing data. Trends in Ecology \& Evolution, 23, 592-596.

Noren K, Godoy E, Dalen L, Meijer T, Angerbjorn A (2016) Inbreeding depression in a critically endangered carnivore. Molecular Ecology, 25, 3309-3318.

Peakall R, Smouse PE (2006) GenAIEx 6: genetic analysis in Excel. Population genetic software for teaching and research. Molecular Ecology Notes, 6, 288-295.

Peakall R, Smouse PE (2012) GenAIEx 6.5: genetic analysis in Excel. Population genetic software for teaching and research-an update. Bioinformatics, 28, 2537-2539.

Pemberton D (1990) Social organisation and behaviour of the Tasmanian devil, Sarcophilus harrisii. University of Tasmania, Hobart.

Pemberton D (2019) The Tasmanian devil: a uniquely threatened animal. Pages 11-22 in C. J. Hogg, S. Fox, D. Pemberton, and K. Belov, editors. Saving the Tasmanian Devil: recovery through sciencebased management CSIRO Publishing, Melbourne, Australia.

Pye RJ, Pemberton D, Tovar C, Tubio JMC, Dunn KA, Fox S, Darby J, Hayes D, Knowles GW, Kreiss A, Siddle HV, Swift K, Lyons AB, Murchison EP, Woods GM (2016) A second transmissible cancer in Tasmanian devils. Proceedings of the National Academy of Sciences of the United States of America, 113, 374-379.

R Core Team (2019) R: A language and environment for statistical computing. Vienna. Available at http://www.R-project.org/.

Raymond M, Rousset F (1995) GENEPOP (version 1.2): population genetics software for exact tests and ecumenicism. Journal of Heredity, 86, 248-249.

Rogers T, Fox S, Pemberton D, Wise P (2016) Sympathy for the devil: captive-management style did not influence survival, body-mass change or diet of Tasmanian devils 1 year after wild release. Wildlife Research, 43, 544-552.

Rousset F (2008) GENEPOP ' 007: a complete re-implementation of the GENEPOP software for Windows and Linux. Molecular Ecology Resources, 8, 103-106.

Sambrook J, Fritsch EF, Maniatis T (1989) Molecular Cloning: a Laboratory Manual. Cold Spring Harbor Laboratory, Cold Spring Harbor

Sinn DL, Cawthen L, Jones SM, Pukk C, Jones ME (2014) Boldness Towards Novelty and Translocation Success in Captive-Raised, Orphaned Tasmanian Devils. Zoo Biology, 33, 36-48.

Stoffel M, Esser M, Kardos M, Humble E, Nichols H, David P, Hoffman J (2016) inbreedR: an R package for the analysis of inbreeding based on genetic markers. Methods in Ecology and Evolution, 7, 13311339.

Storfer A, Epstein B, Jones M, Micheletti S, Spear SF, Lachish S, Fox S (2017) Landscape genetics of the Tasmanian devil: implications for spread of an infectious cancer. Conservation Genetics, 18, 12871297.

Szulkin M, Bierne N, David P (2010) Heterozygosity-fitness correlations: a time for reappraisal. Evolution, 64, 1202-1217.

Thalmann S, Peck S, Wise P, Potts JM, Clarke J, Richley J (2016) Translocation of a top-order carnivore: tracking the initial survival, spatial movement, home-range establishment and habitat use of Tasmanian devils on Maria Island. Australian Mammalogy, 38, 68-79.

Peer) reviewing PDF | (2019:09:40836:3:0:CHECK 22 Apr 2020) 
496

497

498

499

500

501

502

503

504

505

506

507

508

509

510

511

512

513 van Oosterhout C, Hutchinson WF, Wills DPM, Shipley PF (2004) Micro-Checker: software for identifying and correcting genotyping errors in microsatellite data. Molecular Ecology Notes, 4, 535-538.

Weeks AR, Sgro CM, Young AG, Frankham R, Mitchell NJ, Miller KA, Byrne M, Coates DJ, Eldridge MDB, Sunnucks P, Breed MF, James EA, Hoffmann AA (2011) Assessing the benefits and risks of translocations in changing environments: a genetic perspective. Evolutionary Applications, 4, 709-725. Whiteley AR, Fitzpatrick SW, Funk WC, Tallmon DA (2015) Genetic rescue to the rescue. Trends in Ecology \& Evolution, 30, 42-49.

Wise P, Lee D, Peck S, Clarke J, Thalmann S, Hockley J, Schaap D, Pemberton D (2016) The conservation introduction of Tasmanian devils to Maria Island National Park: a response to devil facial tumor disease (DFTD). Pages 166-171 in P. S. Soorae, editor. Global re-introduction perspectives: 2016. Case-studies from around the globe. Gland, Switzerland: IUCN/SSC Re-introduction Specialist Group and Abu Dhabi, UAE: Environment Agency Abu Dhabi.

Wright LI, Tregenza T, Hosken DJ (2007) Inbreeding, inbreeding depression and extinction. Conservation Genetics, 9, 833-843.

Zhang D (2018) rsq: R-squared and related measures. Available at: https://cran.rproject.org/web/packages/rsq/index.html. 


\section{Figure caption}

515 Figure 1: Inbreeding in wild Tasmanian devils at Woolnorth (males and females) over 516 time. Panel A shows individual-level inbreeding recorded as internal relatedness (IR); 517 each point is an individual devil. Panel B shows population-level inbreeding (deviation 518 from Hardy-Weinberg expectations, $F_{I S}$ ); each of the faint grey lines is a microsatellite 519 locus, with the heavy black line illustrating the mean trend. Note: annual monitoring trips 520 were not conducted in 2008, 2010, 2011, 2012 nor 2013. 


\section{Figure 1}

Figure 1: Inbreeding in wild Tasmanian devils at Woolnorth (males and females) over time.

Panel A shows individual-level inbreeding recorded as internal relatedness (IR); each point is an individual devil. Panel B shows population-level inbreeding (deviation from HardyWeinberg expectations, $\mathrm{F}_{15}$ ); each of the faint grey lines is a microsatellite locus, with the heavy black line illustrating the mean trend. Note: annual monitoring trips were not conducted in 2008, 2010, 2011, 2012 nor 2013. 

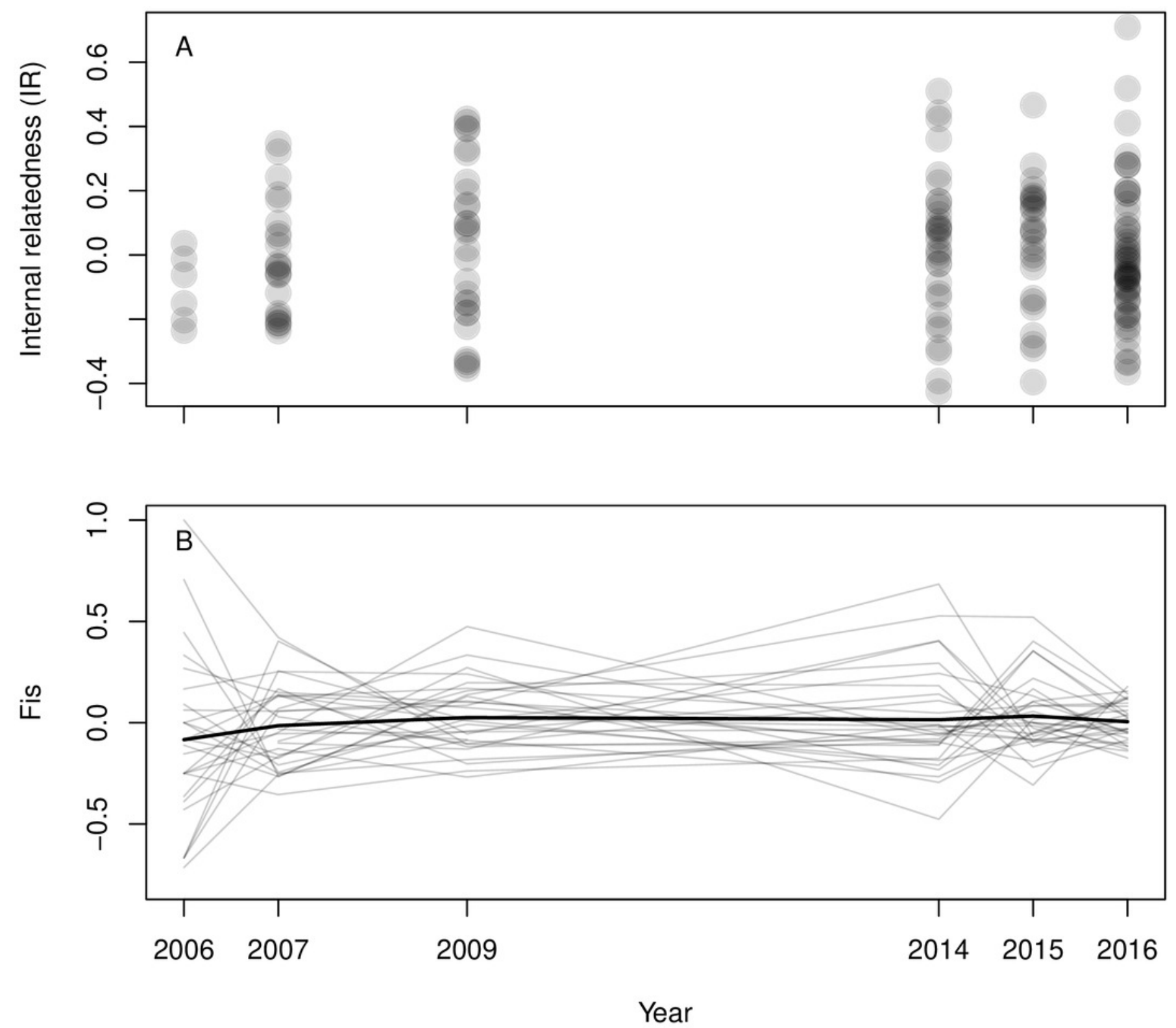


\section{Table $\mathbf{1}$ (on next page)}

Table 1: Genetic variation of 32 polymorphic microsatellite loci in the Woolnorth Tasmanian devil population.

Diversity is measured by number of alleles $(\mathrm{Na})$, observed heterozygosity $\left(\mathrm{H}_{0}\right)$, unbiased estimate of expected heterozygosity $\left(\mathrm{H}_{\mathrm{E}}\right)$ and Hardy-Weinberg Exact test ( $p$-value). Total number of devils $\mathrm{N}=168$. 
1 Table 1: Genetic variation of 32 polymorphic microsatellite loci in the Woolnorth Tasmanian 2 devil population. Diversity is measured by number of alleles $(\mathrm{Na})$, observed heterozygosity $3\left(\mathrm{H}_{\mathrm{O}}\right)$, unbiased estimate of expected heterozygosity $\left(\mathrm{H}_{E}\right)$ and Hardy-Weinberg Exact test ( $p$ 4 value). Total number of devils $\mathrm{N}=168$.

\begin{tabular}{|c|c|c|c|c|c|c|c|c|c|c|c|}
\hline & & & & & & \multicolumn{6}{|c|}{ Estimated null allele frequencies per year ${ }^{1}$} \\
\hline Locus $^{2}$ & $\mathrm{~N}$ & $\mathrm{Na}$ & $\mathrm{H}_{\mathrm{O}}$ & $\mathrm{H}_{\mathrm{E}}$ & p-value & 2006 & 2007 & 2009 & 2014 & 2015 & 2016 \\
\hline Sh2b & 147 & 2 & 0.340 & 0.378 & 0.239 & 0.000 & 0.010 & 0.015 & 0.692 & 0.333 & 0.008 \\
\hline Sh2g & 167 & 3 & 0.701 & 0.646 & 0.053 & 0.000 & 0.000 & 0.000 & 0.000 & 0.000 & 0.100 \\
\hline Sh2i & 168 & 3 & 0.411 & 0.406 & .443 & 0.000 & 0.000 & 0.000 & 0.000 & 0.000 & 0.043 \\
\hline Sh2p & 168 & 3 & 0.667 & 0.617 & 0.300 & 0.000 & 0.000 & 0.000 & 0.046 & 0.061 & 0.042 \\
\hline Sh2v & 168 & 6 & 0.548 & 0.587 & 0.738 & 0.069 & 0.022 & 0.000 & 0.000 & 0.000 & 0.030 \\
\hline Sh3a & 155 & 3 & 0.226 & 0.245 & 0.078 & NA & 0.000 & 0.000 & 0.551 & 0.230 & 0.026 \\
\hline Sh3o & 168 & 4 & 0.464 & 0.522 & 0.129 & 0.027 & 0.000 & 0.054 & 0.000 & 0.006 & 0.082 \\
\hline Sh5c & 160 & 3 & 0.069 & 0.067 & 0.977 & 0.000 & NA & 0.000 & 0.468 & 0.186 & 0.000 \\
\hline Sh6e & 168 & 2 & 0.435 & 0.412 & 0.452 & 0.629 & 0.404 & 0.558 & 0.415 & 0.607 & 0.555 \\
\hline Sh6L & 167 & 2 & 0.138 & 0.139 & 0.943 & 0.000 & 0.000 & 0.056 & 0.156 & 0.000 & 0.000 \\
\hline Sha001 & 164 & 3 & 0.085 & 0.083 & 0.955 & 0.577 & 0.264 & NA & 0.000 & 0.000 & 0.000 \\
\hline Sha008 & 161 & 3 & 0.547 & 0.534 & 0.769 & 0.077 & 0.003 & 0.097 & 0.265 & 0.179 & 0.000 \\
\hline Sha009 & 163 & 4 & 0.319 & 0.297 & 0.954 & 0.516 & 0.199 & 0.000 & 0.145 & 0.019 & 0.000 \\
\hline Sha010 & 161 & 7 & 0.826 & 0.778 & 0.757 & 0.163 & 0.000 & 0.000 & 0.230 & 0.134 & 0.000 \\
\hline Sha011 & 167 & 2 & 0.329 & 0.386 & 0.061 & 0.000 & 0.010 & 0.024 & 0.000 & 0.126 & 0.114 \\
\hline Sha012 & 156 & 3 & 0.487 & 0.538 & 0.000 & 0.000 & 0.016 & 0.191 & 0.307 & 0.331 & 0.024 \\
\hline Sha013 & 162 & 7 & 0.710 & 0.675 & 0.718 & 0.000 & 0.058 & 0.000 & 0.200 & 0.164 & 0.000 \\
\hline Sha014 & 165 & 4 & 0.491 & 0.525 & 0.108 & 0.000 & 0.073 & 0.000 & 0.217 & 0.140 & 0.000 \\
\hline Sha015 & 155 & 2 & 0.471 & 0.471 & 0.978 & 0.000 & 0.114 & 0.000 & 0.542 & 0.176 & 0.000 \\
\hline Sha023 & 156 & 5 & 0.436 & 0.423 & 0.998 & 0.000 & 0.036 & 0.017 & 0.518 & 0.096 & 0.000 \\
\hline Sha024 & 148 & 2 & 0.209 & 0.199 & 0.486 & 0.000 & 0.000 & 0.173 & 0.603 & 0.286 & 0.160 \\
\hline Sha025 & 166 & 2 & 0.193 & 0.231 & 0.037 & 0.217 & 0.107 & 0.000 & 0.139 & 0.194 & 0.006 \\
\hline Sha026 & 164 & 3 & 0.226 & 0.233 & 0.667 & NA & 0.026 & 0.000 & 0.261 & 0.179 & 0.004 \\
\hline Sha028 & 148 & 5 & 0.264 & 0.241 & 0.970 & 0.000 & 0.000 & 0.000 & 0.647 & 0.374 & 0.000 \\
\hline Sha032 & 147 & 3 & 0.061 & 0.060 & 0.986 & NA & 0.000 & 0.000 & 0.707 & 0.419 & NA \\
\hline Sha033 & 166 & 2 & 0.331 & 0.301 & 0.178 & 0.000 & 0.104 & 0.000 & 0.121 & 0.049 & 0.003 \\
\hline Sha034 & 166 & 3 & 0.193 & 0.200 & 0.580 & NA & 0.000 & 0.021 & 0.175 & 0.000 & 0.117 \\
\hline Sha036 & 165 & 2 & 0.248 & 0.295 & 0.048 & 0.000 & 0.000 & 0.024 & 0.261 & 0.094 & 0.122 \\
\hline Sha037 & 164 & 6 & 0.610 & 0.688 & 0.000 & 0.000 & 0.045 & 0.067 & 0.245 & 0.026 & 0.034 \\
\hline Sha039 & 160 & 4 & 0.400 & 0.407 & 0.961 & 0.000 & 0.026 & 0.118 & 0.252 & 0.221 & 0.082 \\
\hline Sha040 & 165 & 5 & 0.612 & 0.599 & 0.000 & 0.000 & 0.000 & 0.171 & 0.048 & 0.124 & 0.019 \\
\hline & 163 & 2 & & & & & & & & & \\
\hline
\end{tabular}

5

6

7

8

9

${ }^{1}$ Estimated using the method of Brookfield (1996); NA indicates a locus that was monomorphic in the specified year dataset.

2 The ten "Sh" markers were developed by Jones et al. (2003); the remaining 22 "Sha" markers were developed by Gooley et al. (2017) 
10 Brookfield JFY (1996) A simple new method for estimating null allele frequency from heterozygote 11 deficiency. Molecular Ecology, 5, 453-455.

Gooley R, Hogg CJ, Belov K, Grueber CE (2017) No evidence of inbreeding depression in a Tasmanian devil insurance population despite significant variation in inbreeding. Scientific Reports, 7, 1830. Jones M, Paetkau D, Geffen E, Moritz C (2003) Microsatellites for the Tasmanian devil (Sarcophilus laniarius). Molecular Ecology Notes, 3, 277-279. 


\section{Table 2 (on next page)}

Table 2: Predictors of reproductive success in female Tasmanian devils.

Predictors have been standardised, and are the conditional average results derived from an information theoretic model selection process (see Methods). 
1 Table 2: Predictors of reproductive success in female Tasmanian devils. Predictors have been

2 standardised, and are the conditional average results derived from an information theoretic

3 model selection process (see Methods); full model sets are provided in Supplementary Table 4 S1.

5

\begin{tabular}{lllcccc}
\hline Model & $\mathbf{N}$ & Predictor & Estimate & SE & RI & $\boldsymbol{R}^{\mathbf{2}^{*}}$ \\
\hline Litter size & 90 & Intercept & -1.073 & 0.146 & & 0.371 \\
& & Age & 0.296 & 0.297 & 0.36 & \\
& & IR & -0.953 & 0.275 & 1.00 & \\
& & Year & -2.367 & 0.285 & 1.00 & \\
\hline Breeding & 90 & Intercept & -0.489 & 0.262 & & 0.311 \\
& & Age & 0.605 & 0.556 & 0.38 & \\
& & IR & -0.737 & 0.521 & 0.49 & \\
& & Year & -2.527 & 0.561 & 1.00 & \\
\hline Litter size 1+ & 36 & Intercept & 1.304 & 0.228 & & 0.312 \\
& & Age & -0.896 & 0.445 & 0.77 & \\
& & IR & -1.047 & 0.439 & 1.00 & \\
& Year & -0.767 & 0.414 & 0.66 & \\
& &
\end{tabular}

6 Abbreviations: $\mathrm{N}=$ sample size, $\mathrm{SE}=$ adjusted standard error, $\mathrm{IR}=$ internal relatedness, $\mathrm{RI}=$ relative 7 importance (sum of Akaike weights)

$8 \quad{ }^{*} R^{2}$ is derived from the global model 


\section{Table 3 (on next page)}

Table 3: Locus-by-locus effects of heterozygosity on litter size of $\mathrm{N}=69$ female devils at Woolnorth with complete genotyping data.

Models with "Locus" IDs include a 0/1 predictor for individual heterozygosity at that locus; the " $\mathrm{H}_{0}$ " model uses multilocus observed heterozygosity, while the "Base" model excludes heterozygosity data altogether. 
1 Table 3: Locus-by-locus effects of heterozygosity on litter size of $\mathrm{N}=69$ female devils at

2 Woolnorth with complete genotyping data. Models with "Locus" IDs include a 0/1 predictor for

3 individual heterozygosity at that locus; the " $\mathrm{H}_{\mathrm{O}}$ " model uses multilocus observed

4 heterozygosity, while the "Base" model excludes heterozygosity data altogether.

\begin{tabular}{|c|c|c|c|c|c|c|c|c|c|c|}
\hline Locus & AIC & $\Delta \mathrm{AIC}_{\text {base }}{ }^{1}$ & $\Delta \mathrm{AIC}_{H_{O}}{ }^{2}$ & $\beta_{0}$ & $S E\left(\beta_{0}\right)$ & $\beta_{\text {year }}$ & $S E\left(\beta_{\text {year }}\right)$ & $\beta_{H_{O}}$ & $S E\left(\beta_{H_{O}}\right)$ & $H_{O}{ }^{3}$ \\
\hline Sh3o & 176.9 & -9.0 & -5.5 & 1.490 & 0.300 & -0.362 & 0.044 & -1.178 & 0.370 & 0.377 \\
\hline Sha32 & 177.8 & -8.1 & -4.6 & 1.422 & 0.290 & -0.388 & 0.045 & -1.810 & 0.623 & 0.072 \\
\hline Sha013 & 178.1 & -7.8 & -4.3 & 0.360 & 0.351 & -0.387 & 0.046 & 1.196 & 0.399 & 0.739 \\
\hline Sha040 & 181.5 & -4.4 & -0.9 & 0.669 & 0.305 & -0.366 & 0.044 & 0.833 & 0.336 & 0.522 \\
\hline Sha039 & 181.9 & -4.0 & -0.5 & 0.951 & 0.264 & -0.392 & 0.048 & 0.889 & 0.374 & 0.348 \\
\hline Sh2g & 182.0 & -3.9 & -0.5 & 0.377 & 0.394 & -0.352 & 0.044 & 0.924 & 0.392 & 0.696 \\
\hline $\mathrm{H}_{\mathrm{O}}$ & 182.4 & -3.5 & - & -0.572 & 0.757 & -0.357 & 0.044 & 4.260 & 1.847 & 0.386 \\
\hline $\operatorname{Sh} 2 p$ & 184.0 & -1.9 & 1.6 & 0.584 & 0.360 & -0.352 & 0.043 & 0.694 & 0.359 & 0.623 \\
\hline Sh6e & 184.1 & -1.8 & 1.7 & 0.716 & 0.318 & -0.354 & 0.043 & 0.639 & 0.330 & 0.522 \\
\hline Sh6L & 185.1 & -0.8 & 2.6 & 0.974 & 0.268 & -0.355 & 0.043 & 0.795 & 0.471 & 0.130 \\
\hline Sha023 & 185.3 & -0.6 & 2.8 & 0.857 & 0.293 & -0.360 & 0.043 & 0.527 & 0.327 & 0.464 \\
\hline Sha037 & 185.6 & -0.3 & 3.1 & 0.779 & 0.325 & -0.354 & 0.043 & 0.503 & 0.332 & 0.551 \\
\hline Sha001 & 185.7 & -0.2 & 3.3 & 1.148 & 0.263 & -0.358 & 0.043 & -1.206 & 0.878 & 0.058 \\
\hline Sh3a & 185.8 & -0.1 & 3.4 & 1.250 & 0.286 & -0.358 & 0.043 & -0.514 & 0.358 & 0.304 \\
\hline Base $^{4}$ & 185.9 & - & 3.5 & 1.090 & 0.257 & -0.357 & 0.043 & - & - & - \\
\hline Sha024 & 186.3 & 0.4 & 3.9 & 1.177 & 0.269 & -0.355 & 0.043 & -0.539 & 0.436 & 0.203 \\
\hline Sha011 & 186.5 & 0.6 & 4.1 & 0.915 & 0.295 & -0.351 & 0.043 & 0.397 & 0.334 & 0.348 \\
\hline Sh2b & 186.7 & 0.8 & 4.2 & 0.965 & 0.278 & -0.362 & 0.043 & 0.369 & 0.332 & 0.420 \\
\hline Sh2i & 186.7 & 0.8 & 4.2 & 0.959 & 0.282 & -0.361 & 0.044 & 0.364 & 0.330 & 0.420 \\
\hline Sha028 & 186.7 & 0.8 & 4.2 & 1.216 & 0.285 & -0.359 & 0.043 & -0.392 & 0.358 & 0.319 \\
\hline Sha010 & 186.7 & 0.8 & 4.3 & 1.493 & 0.458 & -0.362 & 0.044 & -0.459 & 0.421 & 0.812 \\
\hline Sha025 & 186.9 & 1.0 & 4.5 & 1.013 & 0.268 & -0.360 & 0.043 & 0.365 & 0.371 & 0.261 \\
\hline Sha015 & 187.2 & 1.3 & 4.8 & 0.990 & 0.282 & -0.362 & 0.044 & 0.274 & 0.330 & 0.493 \\
\hline Sha012 & 187.5 & 1.6 & 5.0 & 0.994 & 0.294 & -0.359 & 0.043 & 0.214 & 0.324 & 0.507 \\
\hline Sha026 & 187.6 & 1.7 & 5.2 & 1.050 & 0.267 & -0.360 & 0.043 & 0.194 & 0.362 & 0.304 \\
\hline Sha008 & 187.6 & 1.7 & 5.2 & 0.990 & 0.317 & -0.358 & 0.043 & 0.176 & 0.332 & 0.609 \\
\hline Sha042 & 187.7 & 1.8 & 5.2 & 1.140 & 0.280 & -0.356 & 0.043 & -0.161 & 0.343 & 0.362 \\
\hline Sha033 & 187.7 & 1.8 & 5.3 & 1.181 & 0.339 & -0.362 & 0.045 & -0.143 & 0.338 & 0.391 \\
\hline Sh5c & 187.8 & 1.9 & 5.4 & 1.077 & 0.262 & -0.356 & 0.043 & 0.168 & 0.675 & 0.058 \\
\hline Sha014 & 187.9 & 2.0 & 5.5 & 1.104 & 0.293 & -0.356 & 0.043 & -0.034 & 0.325 & 0.536 \\
\hline Sha034 & 187.9 & 2.0 & 5.5 & 1.082 & 0.270 & -0.356 & 0.043 & 0.036 & 0.417 & 0.174 \\
\hline Sha009 & 187.9 & 2.0 & 5.5 & 1.081 & 0.309 & -0.356 & 0.043 & 0.017 & 0.327 & 0.420 \\
\hline Sha036 & 187.9 & 2.0 & 5.5 & 1.096 & 0.300 & -0.357 & 0.045 & -0.017 & 0.388 & 0.203 \\
\hline Sh2v & 187.9 & 2.0 & 5.5 & 1.086 & 0.298 & -0.357 & 0.043 & 0.009 & 0.323 & 0.493 \\
\hline
\end{tabular}

$5{ }^{1}$ Difference in AIC between the focal model and the "base" model, which excludes genetic data

62 Difference in AIC between the focal model and the multilocus heterozygosity model

$7 \quad 3$ Observed rate of heterozygosity in the sample set, for the specified locus

84 Sh2L was monomorphic in this subset of devils; the model is therefore excluded from the table, as it

9 is identical to the "base" model. 